\title{
Integrated defence workforces: Challenges and enablers of military-civilian personnel collaboration
}

DOI 10.2478/jms-2019-0004

Received September 26, 2018; accepted August 23, 2019

Abstract: Defence organisations are unique in that they comprise integrated military and civilian personnel working in partnership with each other (e.g., in headquarters, on bases, on missions, in academic settings). Many defence civilians are supervised by military supervisors and managers, while others are themselves responsible for managing military personnel. At the same time, despite often high levels of partnership and integration, military and civilian personnel are governed by very different personnel management systems, and have distinct cultures. These factors can affect the nature and quality of the collaboration and influence personnel outcomes and organisational effectiveness. Indeed, defence organisations are increasingly recognizing the importance of optimizing integration between their military and civilian workforces, with many adopting organisational terms implying that the military and civilian workforces form a cohesive whole: the Defence Team (Canada), the Whole Force Concept (United Kingdom), One Defence Team (Sweden), and Total Defence Workforce (New Zealand).

This paper presents results from the Military-Civilian Personnel Survey (MCPS), which was administered in 11 nations as part of a NATO Research Task Group on the topic of military-civilian personnel collaboration and

\footnotetext{
*Corresponding author: Irina Goldenberg, from Director General Military Personnel Research and Analysis (DGMPRA) in the Department of National Defence, Canada; NDHQ (Carling), 60 Moodie Dr, Bldg CC-9, 9S.2.W30.01, Ottawa, Canada, Tel.: 613-901-9776, E-mail: irina.goldenberg@forces.gc.ca Manon Andres, Netherlands Defense Academy, Faculty of Military Sciences

Johan Österberg, Department of Security, Strategy and Leadership, Swedish Defence University

Sylvia James-Yates, Army Headquarters, Ministry of Defence, United Kingdom

Eva Johansson, Department of Security, Strategy and Leadership, Swedish Defence University

Sean Pearce, from Director General Military Personnel Research and Analysis (DGMPRA) in the Department of National Defence, Canada
}

integration (NATO STO HFM RTG-226). This survey was the first systematic examination of large samples of military and civilian respondents, and the first to examine militarycivilian relations from the perspective of both military and civilian personnel. The results presented here are based on three open-ended questions included in the survey, which asked respondents to identify 1 ) the most important factors for establishing and maintaining positive military-civilian personnel work culture and relations, 2) the challenges of working in a military-civilian environment, and 3) the main advantages of working in a military-civilian environment. Results of 5 nations, including Canada, Netherlands, New Zealand, Sweden, and the United Kingdom ( $n=1,513$ military respondents and $n=2,099$ defence civilians) are presented. Results indicate that mixed military-civilian work environments present both unique challenges and advantages, and identified the factors considered to be important for enhancing integration and collaboration between military and civilian personnel. Given that many cross-national patterns emerged, these findings provide useful insights for enhancing military and civilian personnel integration and collaboration across nations.

*Adapted from the material first reported in Goldenberg, I. \& Febbraro, A.R. (2018; in publication). Civilian and Military Personnel Integration and Collaboration in Defence Organizations. NATO Science and Technology Organization Technical Report - STO-TR-HFM-226. DOI 10.14339/STO-TR-HFM-226. ISBN: ISBN 978-92-837-2092-8.

Keywords: Defence Team; Whole Force Concept; One Defence Team; Total Defence Workforce; military-civilian collaboration

\section{Military-Civilian Integration and Collaboration}

This article focuses on a specific type of military-civilian relations which occurs within defence organizations between military personnel and civilian public servants. In 
recent years, there has been a plethora of research focusing on civilian contractors working for private military and security companies (PMSCs; Schaub and Kelty 2016; Schwartz and Church, 2013). However, although there are likely many commonalities between civilian contractors and civilian public servants (or "defence civilians") with respect to their collaboration with military personnel, there is a paucity of research on this latter group (Goldenberg and Febbraro 2018a). This is surprising given that civilian public servants are employees of defence departments or ministries and they are in that sense more "proximal" to their military counterparts as compared with civilian contractors who are generally employed by PMSCs (Kochems 2006; Schaub and Kelty 2016). Nonetheless, although relations between military personnel and defence civilians have not historically been the centre of specific consideration, many nations are now explicitly focusing on the importance of a well-integrated and functioning military-civilian defence workforce, as evident by the emergence of organizational terms such as the Defence Team (Canada), the Whole Force Concept (the United Kingdom), One Defence Team (Sweden), and Total Defence Workforce (New Zealand) and organizational documents related to human resources plans and strategies (Australian Ministry of Defence 2014; Österberg and Johansson 2018; Parry et al. 2016).

Why is military-civilian personnel collaboration important? Most defence organizations are made up of military service members and civilian public servants, and an analysis of 12 western nations shows that civilians usually make up significant proportions (20-35\%) of total defence workforces (Goldenberg and Febbraro 2018b). These personnel work together in a variety of contexts, including in headquarters, on bases, in military academic institutions, and increasingly, on deployments (Dunigan et al. 2018). Indeed, there is a high degree of integration between military and civilian personnel. For example, recent cross-national research showed that approximately $90 \%$ of civilian and military personnel reported that they work beside one another and are co-located. Out of these, about $80 \%$ of military personnel reported interacting with civilian co-workers on a daily basis. Even greater proportion of civilians reported interacting with military co-workers on a daily basis (Goldenberg et al. 2018a). Moreover, many defence civilians are supervised by military supervisors and managers, while others are themselves responsible for managing military personnel.

Despite this high degree of integration, there are of course important distinctions between these groups of personnel. Perhaps most notably, military and civilian personnel are governed by very different personnel management systems and conditions of service/employment.
For example, while civilian public servants may be hired at any level, most military personnel are recruited in their youth and trained by the organization to acquire their military and occupational skills (i.e. they are "grown from within"). Promotion through the ranks is based on military performance appraisal systems reflecting unique requisites for military members. Perhaps, most notably, military personnel's conditions of service entail unlimited liability, and in extreme cases even death. In addition to these differences in human resource systems, military members and defence civil servants have distinct cultures, communication styles, and approaches to leadership that reflect their different histories, values, roles, and policies (Goldenberg and Febbraro 2018b). These factors can affect the nature of collaboration between these integrated workforces and influence personnel outcomes and organizational effectiveness. Indeed, research shows that military and civilian personnel who engage in positive personnel collaboration show greater job satisfaction, work engagement, and commitment to the defence organization (Goldenberg et al. 2018b; Parry et al. 2016).

Several small-scale studies have indicated that there are areas of concern and that this is an important area of inquiry. For example, examining well-being and retention of defence civilians through 26 focus groups at Canadian Armed Forces bases, McKee and Williams (2007) reported that civilian employees felt that military personnel received greater workplace advantages, that their skills and expertise were not recognized to the same degree as those of their military counterparts, and that the military rotational cycle had negative impact on their work. This and other research also indicated that military leaders and supervisors are generally ill-equipped to carry out civilian human resource responsibilities (e.g. Lalonde 2011; McKee and Williams 2007). Similarly, examining relations between military professors and civilian academics in teaching roles at military academic institutions, Mastroianni (2018) discussed important underlying cultural differences between the civilian and military personnel which sometimes contributed to tensions between the two groups. In a unique case study in the Ministry of Defence in the United Kingdom in which civilians were the majority group, Shaw and JamesYates (2018) also highlighted how cultural and even language differences, intergroup stereotypes, and general lack of understanding about each other's roles and personnel management systems resulted in a variety of issues between military members and defence civilians. Given the lack of dedicated research in this domain, a NATO Science and Technology Research Task Group was established to study military and civilian personnel work culture and relations in defence organizations through theoretical and empirical 
Tab. 1: Military-civilian personnel survey: sample characteristics by nation

\begin{tabular}{|c|c|c|c|c|c|c|c|c|c|c|c|c|}
\hline & \multicolumn{2}{|l|}{ Canada } & \multicolumn{2}{|c|}{ The Netherlands } & \multicolumn{2}{|c|}{ New Zealand } & \multicolumn{2}{|l|}{ Sweden } & \multicolumn{2}{|c|}{$\begin{array}{l}\text { The United } \\
\text { Kingdom }\end{array}$} & \multicolumn{2}{|l|}{ Total } \\
\hline & Military & Civilian & Military & Civilian & Military & Civilian & Military & Civilian & Military & Civilian & Military & Civilian \\
\hline$N$ & 663 & 1,149 & 490 & 444 & 396 & 274 & 213 & 85 & 386 & 981 & 2,148 & 2,933 \\
\hline \multicolumn{13}{|c|}{ Age (years) } \\
\hline $16-24$ & 2.1 & 0.3 & - & - & 22.4 & 0.8 & - & 1.2 & 5.2 & 0.9 & 6.0 & 0.5 \\
\hline $25-34$ & 20.7 & 8.3 & 13.3 & 10.6 & 22.9 & 12.9 & 1.4 & 15.5 & 21.1 & 8.6 & 17.8 & 9.3 \\
\hline $35-44$ & 34.4 & 17.4 & 24.2 & 22.3 & 28.2 & 21.3 & 26.9 & 28.6 & 31.8 & 14.8 & 30.0 & 17.8 \\
\hline $45+$ & 42.8 & 74.0 & 62.5 & 67.0 & 26.6 & 65.0 & 71.6 & 54.8 & 41.9 & 75.7 & 46.2 & 72.4 \\
\hline \multicolumn{13}{|l|}{ Sex } \\
\hline Male & 82.1 & 57.4 & 90.9 & 74.1 & 81.6 & 61.2 & 96.7 & 47.6 & 87.5 & 59.8 & 86.2 & 60.1 \\
\hline Female & 17.9 & 42.6 & 9.1 & 25.9 & 18.4 & 38.8 & 3.3 & 52.4 & 12.5 & 40.2 & 13.8 & 39.9 \\
\hline \multicolumn{13}{|l|}{$\begin{array}{l}\text { Years of } \\
\text { Service }\end{array}$} \\
\hline$<4$ & 3.6 & 20.3 & 1.4 & 6.0 & 4.2 & 8.0 & - & 24.1 & 7.4 & 9.6 & 8.1 & 15.6 \\
\hline $5-14$ & 27.7 & 26.5 & 15.6 & 33.7 & 21.7 & 34.6 & 6.2 & 34.9 & 21.3 & 37.1 & 25.0 & 30.8 \\
\hline $15-24$ & 30.5 & 18.2 & 21.2 & 15.4 & 37.1 & 37.6 & 30.6 & 12.0 & 31.1 & 23.4 & 25.2 & 19.1 \\
\hline $25+$ & 38.2 & 35.0 & 61.7 & 44.9 & 20.3 & 11.8 & 63.2 & 28.9 & 40.2 & 29.9 & 41.8 & 33.4 \\
\hline
\end{tabular}

Note: Values are the percentage of respondents in each category.

analyses. As part of a broader programme of work, a largescale cross-national survey - the Military-Civilian Personnel Survey (MCPS) - was developed to identify key aspects of military-civilian working relations and dynamics. This paper presents exploratory empirical results based on analyses of military and civilian participants' responses to the open-ended questions presented in the MCPS regarding the benefits and challenges of mixed military-civilian work environments, as well as factors for facilitating positive collaboration between these workforces. ${ }^{1}$

\section{Method}

\subsection{Measures}

The MCPS was designed to examine unique issues central to the partnership between military and civilian personnel in the defence organizations of the participating nations. In addition to a broad range of closed-ended scales and items examining various aspects of military-civilian work culture and relations such as intergroup perceptions, quality of communication, and effects on professional

1 These analyses are reproduced or adapted from the material first reported in Goldenberg et al. (2018c). However, instead of presenting percentage of theme categorizations that each respective theme represented, the data were reanalysed to present the percentage of respondents who evinced each theme. development, respondents were also asked to describe in their own words: (1) the challenges of working in a military-civilian environment, (2) the main advantages of working in a military-civilian environment, and (3) the most important factors for establishing and maintaining positive military-civilian personnel work culture and relations. Analysis of the responses to these open-ended questions is the focus of this paper.

\subsection{Sampling and survey administration}

The results of five nations, including Canada, the Netherlands, New Zealand, Sweden, and the United Kingdom, which administered the open-ended MCPS questions were included in this analysis. ${ }^{2}$ The sizes of the military and civilian MCPS samples for each participating nation are presented in Table 1.

The sampling approaches and modes of administration were tailored to suit the population characteristics and organizational practices and requirements of the participating national defence organizations. A comprehensive review of best practices in cross-national research indicated that international survey processes are generally more complex than surveys conducted within a single nation and that different modes of administration may be

2 The open-ended MCPS questions were also administered in Estonia but are not included here due to small sample sizes of 63 military and 82 civilian respondents. 
more appropriate, or indeed more feasible, in different organizations (Goldenberg 2014). Due to the heterogeneity of target populations and organizations, no single approach is likely to be best suited across all nations and flexibility in data collection methods is warranted (Pennell et al. 2011). As such, sampling and administration varied depending on the specifics of the nation and the population surveyed as described below.

\subsubsection{Canada}

The Canadian military sample was based on a stratified random sample of Regular Force Canadian Armed Forces personnel, stratified by rank and military service (Army, Navy, and Air Force). Participants selected for the survey were notified by e-mail at their work e-mail address and provided a Uniform Resource Locator (URL) to a survey in their official language of choice (French or English). Three reminders were sent for participation while the survey links were active. In total, 663 regular force personnel and 1,149 civilian personnel completed the survey, resulting in response rates of 36.0 and $28.8 \%$ for military and civilian personnel, respectively.

\subsubsection{The Netherlands}

In the Netherlands, personnel were randomly selected from all seven organizational departments: Navy, Army, Air Force, Marechaussee, Defence Materiel Organisation, Joint Support Command, and Central Staff. However, only employees working in staff departments of the Navy, Army, Air Force, and Marechaussee were selected because operational units mainly consist of military personnel. Those who were selected for the survey received an invitation with a URL to complete the questionnaire in Dutch at their work e-mail address. An electronic reminder was sent 2 weeks after the initial invitation to participate. In total, 490 military personnel and 444 civilian personnel completed the survey, yielding a response rate of 39.0 and $36.0 \%$ for military and civilian personnel, respectively.

\subsubsection{New Zealand}

New Zealand Defence Force personnel were contacted through the organization's intranet e-mail system, and mailers were sent out to groups known to have lower response rates to surveys. The overall sample was obtained through random selection. The survey was administered in
English. In total, 396 military and 274 civilian respondents completed the survey, yielding response rates of 20.0 and $41.0 \%$ for military and civilian personnel, respectively.

\subsubsection{Sweden}

In the Swedish Defence Organisation, personnel were selected from two departments from the headquarters, (i.e. the Production and the Operational Staffs) through means of convenience sampling. A paper format of the survey was administered in Swedish. In total, 213 military members and 85 civilian personnel completed the survey, representing response rates of 55.0 and $25.0 \%$ for military and civilian personnel, respectively.

\subsubsection{The United Kingdom}

In the United Kingdom Ministry of Defence, information about the survey was disseminated to employees through the Defence intranet website, inviting defence personnel to partake in the survey. As such, participation was obtained through self-selection, generating an opportunity sample. The English version of the survey was administered electronically. In total, 981 civilian personnel and 386 military personnel completed the survey.

\subsection{Samples}

As shown in Table 1, most of the military respondents in the samples were 35 years of age or older, whereas civilian respondents tended to be older than the military respondents (the largest proportion was 45 years and above). With respect to sex, the military samples were predominantly male, whereas the civilian samples were more evenly distributed across the sexes, with some exceptions (i.e. the Netherlands). Years of service varied across organizations, but they tended to be longer for military as compared with civilian respondents.

\subsection{Qualitative data analysis}

For each of the three open-ended questions, the responses were coded into categories using pre-established coding schemes (Bremner et al. 2013; Goldenberg 2013). The coding scheme for each question had 12-14 themes or categories. Complex responses, which pertained to multiple themes, were coded under all pertinent categories. 


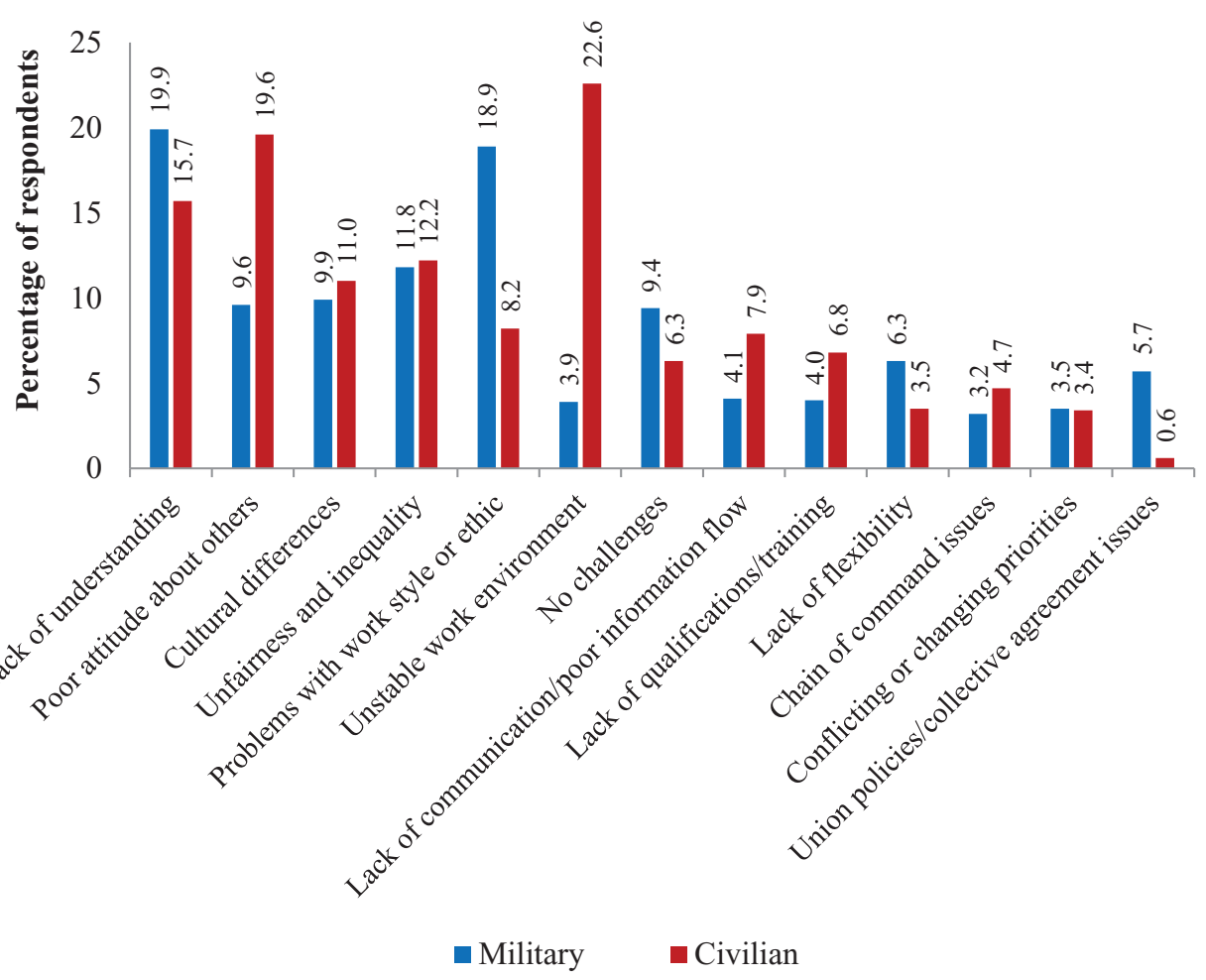

Fig. 1: Challenges experienced working in a mixed military-civilian work environment.

All responses deemed to be unrelated to the initial question were coded as "not applicable." Comments that were unique and could not be aggregated into a single category were coded as “other." Participants' responses to each question were complex and often contained multiple themes; thus the number of theme categorizations for each question exceeded the number of survey respondents.

The percentage of military and civilian personnel which cited each theme, across all nations combined, are presented in the results section. Following this, the five most prevalent themes that captured the majority of open-ended responses are discussed and example quotes representing each of these themes are provided. Given that the top five themes identified as being important for maintaining military and civilian relations were similar for military and civilian respondents, these themes are discussed for military and civilian respondents together so as to avoid repetition.

\section{Results}

\subsection{Challenges of working in a mixed military-civilian environment}

The first open-ended question asked respondents: "What are the main challenges you experience working in a mixed military-civilian work environment?” A total of 1,505 military respondents and 2,095 civilian respondents provided answers to this question after accounting for responses that were deemed "not applicable." Figure 1 provides the percentages of military and civilian personnel that mentioned each respective theme in response to this question.

As shown in Figure 1, the top six challenges ${ }^{3}$ identified overall (which represent $70.6 \%$ of all theme categorizations for this question) were lack of understanding, poor attitude about others, cultural differences, lack of fairness or unequal treatment, perceived issues with work style or work ethic of one of the groups by the other group, and unstable work environment. Military personnel were much more likely than civilians to indicate that issues related to civilians' working style or work ethic contributed to military-civilian integration challenges $(8.2 \%$ of civilians and $18.9 \%$ of military respondents mentioned this theme), and were somewhat more likely to indicate that lack of understanding regarding the other group's roles, conditions of employment, or culture contributed to military-civilian integration challenges ( $15.7 \%$ of civilians and $19.9 \%$ of military respondents mentioned this theme).

3 The top six themes were discussed for the first question because of the relatively high frequency with which the sixth theme was mentioned, particularly by civilian personnel. 
Civilians, on the other hand, were much more likely to indicate that unstable work environment was a challenge stemming from working in a mixed military-civilian work environment, with this theme being the most frequently cited challenge by civilians but rarely cited by military respondents $(22.6 \%$ of civilians and $3.9 \%$ of military respondents mentioned this theme). Each of these themes is elaborated below and examples are provided.

\subsubsection{Lack of understanding}

Lack of understanding was the most common challenge identified by military respondents and the third most common challenge identified by civilian respondents. Respondents who mentioned this theme noted lack of understanding regarding each other's roles, abilities, culture, perspectives, conditions of service or employment, and organizational policies and procedures related to one of the groups. The following responses illustrate this theme:

Lack of appreciation of each other's customs, experience, and knowledge. (The Netherlands, military)

To get civilians to understand that the SAF is no ordinary corporation, working 9-5. To get them to understand which demands are put on them, international service with the risk of getting hurt or killed. (Sweden, military)

Lack of understanding that civilian personnel don't fall under the Armed Services Act and all that goes with that. (New Zealand, civilian)

\subsubsection{Poor attitudes about others}

Another commonly cited challenge was poor attitudes about others, which was the second most commonly cited theme of civilians and the fifth most commonly cited theme of military respondents. Responses in this theme included comments regarding the challenge of working with military or civilians who had a sense of superiority or entitlement, envy, criticism, and/or lack of respect for their co-workers in the "other" group. The following responses illustrate this theme:

Too much of an attitude that: "I'm unionized/Public Servant and I resent military authority telling me I have to perform outside of my Collective Agreement.” The Military members come and go ... the Civilian staff just hold out and wait for the "new batch to come in for indoctrination." (Canada, military)

Civilians are treated as second-class citizens, their work is undermined. Military always take the credit; but moreover, military regardless of rank do not listen or acknowledge their civilian counterparts/seniors authority. (The United Kingdom, civilian)

Some Military personnel, thankfully a minority in my experience, seem to view civilian personnel as an inconvenience or wannabe's filling positions that should be military, rather than figuring out that civilian staff are there to enable the military personnel to concentrate on the military aspects of the job. (New Zealand, civilian)

\subsubsection{Cultural differences}

A similar percentage of military and civilian respondents cited cultural differences as a challenge, with this being the fourth and fifth most commonly cited theme for military and civilian personnel, respectively. Comments coded in this theme emphasized differences between military and civilian cultures and issues that sometimes arise from cultural differences in viewpoints, values, and styles of communication. The following responses illustrate this theme:

The differing cultures and processes that drive civilian and military careers. This creates a cultural divide that must be effectively bridged to ensure that the defence team is all moving in the same direction. (Canada, military)

Cultural differences; speaking the same language; a good connection between military customs, norms, and values and that of civilian personnel. (The Netherlands, civilian)

\subsubsection{Work style or ethic}

Perceived problems with work style or work ethic was the second most frequently cited theme of military respondents and the sixth most commonly cited theme of civilians. Responses within this theme related to issues arising from incompatible work styles (e.g. long-term rather than short-term focus), as well as comments about one of the group's commitment, dedication, and working hours. The following responses illustrate this theme:

Having to reduce my expectations regarding speed of response. Coming from a can do, get it done front line environment to one that gets there eventually. (The United Kingdom, military)

Different views of job and work perceptions; different views and work ethos; different mentality. (The Netherlands, military)

\subsubsection{Unstable work environment}

The most common challenge cited by civilians was the unstable work environment resulting from frequent turnover due to posting and deployments of military personnel, 
resulting in loss of corporate knowledge and compromising continuity and efficiency, too many absences by military personnel, and poor timing of postings. A small percentage of military respondents also recognized and commented on this challenge. The following responses illustrate this theme:

Military personnel leaving after 3 years or if they are deployed. Colleagues' competences are lost. Lessons learned are lost. (The Netherlands, civilian)

Job rotation in senior positions makes decision making and continuity of decisions challenging as new people often want to revisit previous decisions/directions. (New Zealand, civilian)

\subsubsection{Unfairness and inequality}

Issues related to fairness and equality were the third and fourth most commonly cited challenges for military and civilian personnel, respectively. Responses categorized under this theme related to perceived lack of fairness or equality in terms of working hours, pay, procedures, professional development and career advancement opportunities, and other policy-related issues. The following responses illustrate this theme:

Differences in regulations; differences in salaries and rights that military personnel have and civilians not. (The Netherlands, civilian)
Bias given to military personnel for job opportunities, regardless of merit. (New Zealand, civilian)

\subsubsection{Challenges of working in a mixed military-civilian environment: cross-national comparison}

Responses between the nations were compared, as shown in Figure 2. Given the degree of overlap between the military and civilian responses, and for the sake of parsimony, cross-national analyses on the combined responses of military and civilian personnel are presented. An overall pattern can be observed in that the top six themes are largely similar across the nations (and the six least common themes being least commonly cited for all nations), with some cross-national variability. For example, a fair proportion of respondents in the Netherlands indicated that there are "no challenges" with respect to a mixed military-civilian work environment $(16.7 \%)$, and relatedly, were less likely to indicate that poor intergroup attitudes was an issue (5.4\%). Respondents from New Zealand were also somewhat more likely than other nations to indicate that there were no challenges (11.7\%). Although lack of understanding was an oft-cited challenge across the nations, this factor was identified more frequently by Swedish military personnel

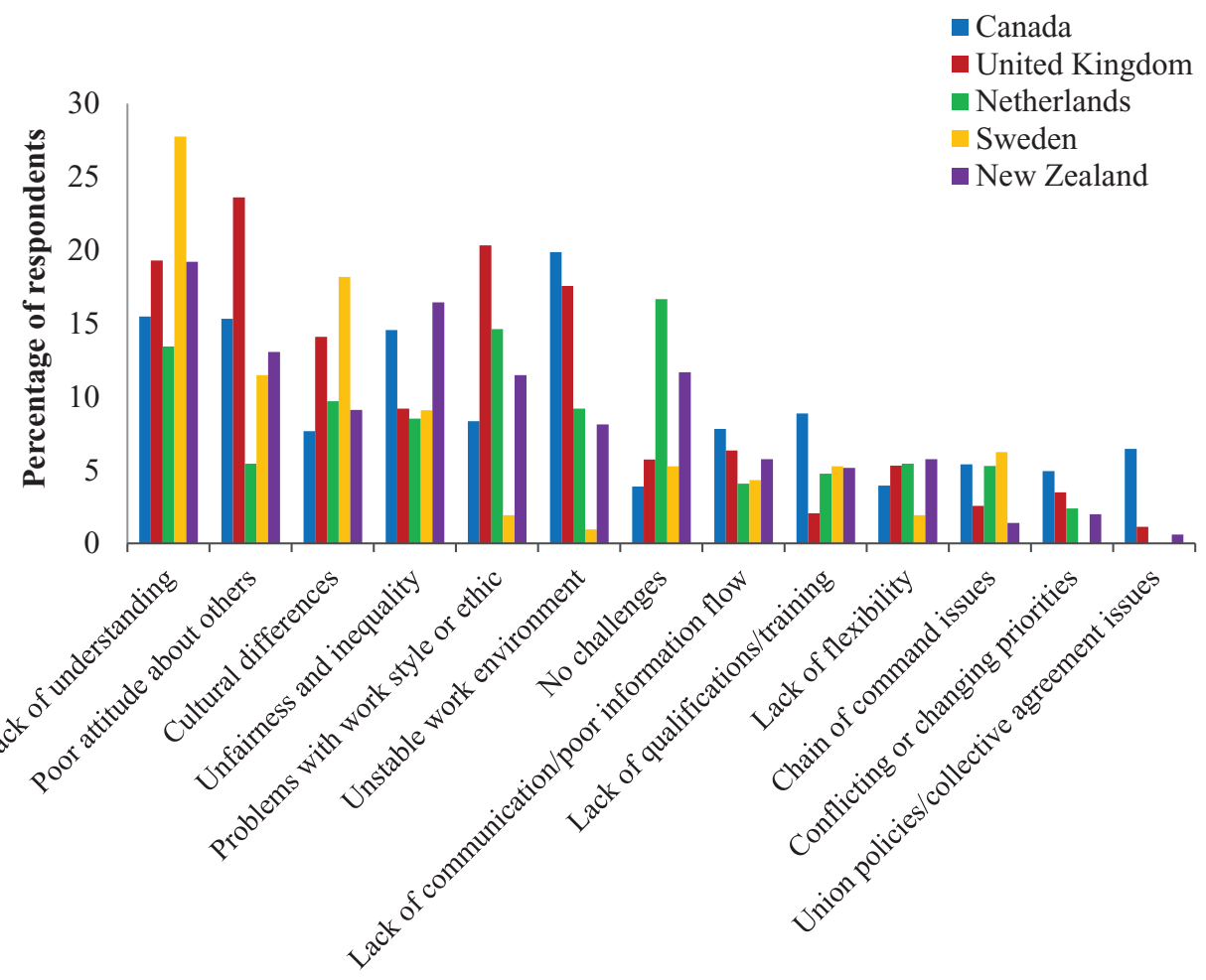

Fig. 2: Challenges experienced working in a mixed military-civilian work environment. 
(33.5\%) as compared with military personnel in the other nations. Similarly, although a frequent theme across all nations, respondents in the United Kingdom were particularly likely to cite poor attitudes towards others $(23.6 \%)$ and differences in work style and ethic $(20.3 \%)$ as key issues. Further, contrary to the overall trend, Sweden was the only nation in which problems with work style or ethic were not considered a notable challenge. Another outlier, Canada was the only nation where union policies/collective agreement issues were reported with any notable frequency $(6.4 \%)$. In general, the top six themes were most different for the Swedish responses, accounting for a fair degree of the cross-national variability.

\subsection{Positive aspects of working in a mixed military-civilian environment}

The second open-ended question asked respondents: "What are the most positive aspects of working in a mixed military-civilian work environment?" A total of 1,472 military respondents and 2,010 civilian respondents provided answers to this question after accounting for responses that were deemed "not applicable." Figure 3 provides the percentages of military and civilian personnel which mentioned each respective theme in response to this question.

As shown in Figure 3, although the five most frequently cited themes (which represent $70.2 \%$ of all theme categorizations for this question) were generally common to both military and civilian personnel (with the exception of stability/continuity), there were some notable differences in the frequencies with which these were mentioned by respondents in the two respective groups. In particular, although military and civilians both identified diverse perspectives as the main benefit of a mixed military-civilian work environment, military personnel were much more likely to mention this factor as compared with civilians $(26.0 \%$ of civilians and $38.5 \%$ of military respondents mentioned this theme). Relatedly, additional knowledge and skills were more likely to be mentioned by military than by civilian respondents, although this theme was relatively common for both $(13.5 \%$ of civilians and $20.1 \%$ of military respondents mentioned this theme). Further, military were much more likely than civilians to indicate stability and continuity as a key benefit, with over a quarter of military respondents mentioning this factor but only a negligible percentage of civilian respondents mentioning it (5.2\% of civilians and $26.9 \%$ of military respondents mentioned this theme).

Examining the general pattern of responses, military tended to highlight fewer main positive aspects (i.e. almost all their responses centred on four themes, including diverse perspectives, additional knowledge and skills, stability and continuity, and learning opportunities), whereas civilians tended to discuss a greater range of factors, and their responses were more distributed across these dimensions (e.g. civilians were more likely than military to mention that working in a mixed military-civilian environment contributed to a positive organizational culture, more effective and efficient performance, greater opportunities for collaboration, and contributed to organizational identification). Each of these themes is elaborated below and examples are provided.

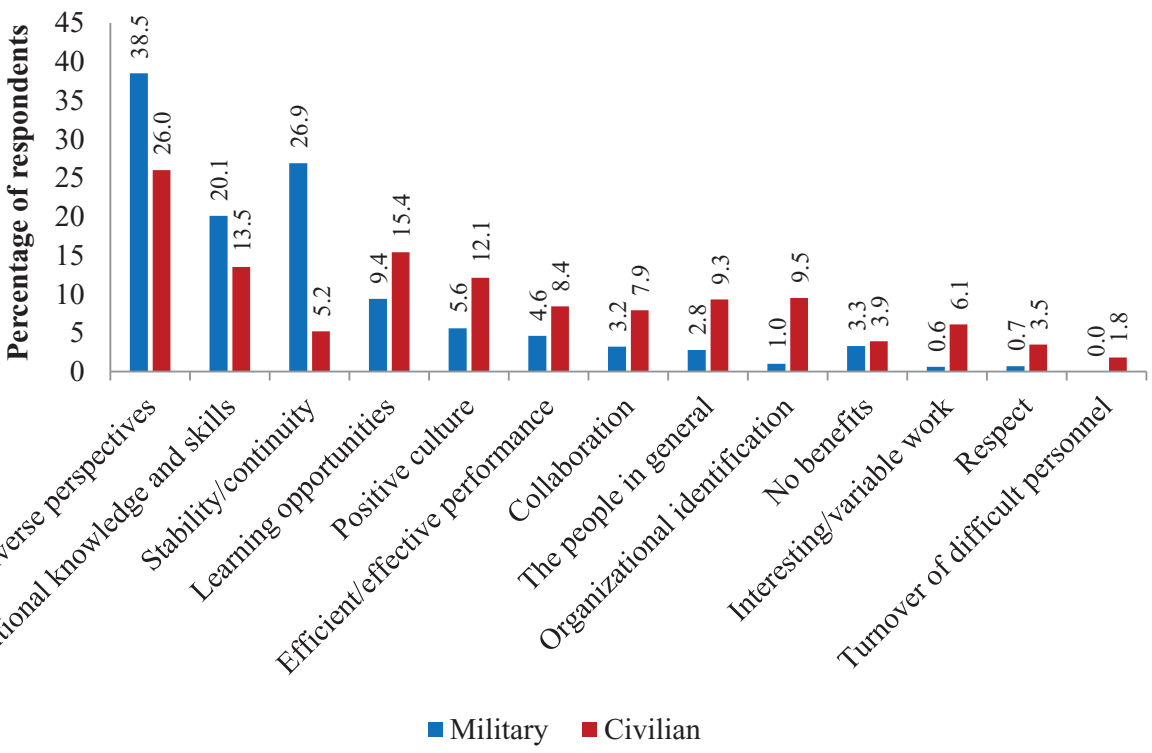

Fig. 3: Positive aspects of working in a mixed military-civilian work environment. 


\subsubsection{Diverse perspectives}

Diverse perspectives were the most frequently cited benefit for both military and civilian personnel, although a much greater proportion of military respondents highlighted this benefit. Comments coded in this theme related to the benefit of having exposure to new or diverse perspectives of both military and civilians, often due to their different backgrounds, culture, skills, job experience, or history. Respondents also frequently noted that these diverse perspectives were beneficial for making more effective decisions. The following responses illustrate this theme:

Develops wider understanding, improves management skills, and offers different perspectives. (The United Kingdom, military)

A more broad spectrum of ideas and considerations that helps the organisation agility to adapt and overcome problems better and more quickly. (New Zealand, military)

A great variety of different kinds of competencies that contributes. (Sweden, civilian)

\subsubsection{Additional knowledge and skills}

Additional knowledge and skills were the third most frequently cited benefit by both military and civilian personnel (and may be somewhat related to diverse perspectives). Responses coded in this theme related to working with high performing or skilled individuals who possess unique and valuable skillsets. Another common aspect coded within this theme was mentions of civilians having high level of competence and their willingness to pass on corporate knowledge. The following responses illustrate this theme:

Military and civilian personnel complement each other. The knowledge and experience is more diverse and broader than in a purely military environment. (The Netherlands, military)

The SAF have been professionalized with the influx from civilian competence. (Sweden, military)

Military members bring with them new work experiences and knowledge from other locations that benefit local operations. (Canada, civilian)

\subsubsection{Stability and continuity}

Stability and continuity were the second most commonly cited benefit for military personnel, although they were mentioned relatively infrequently by civilians. Many military respondents indicated that the continuity and corporate memory provided by civilian personnel is beneficial because it supplements areas of discontinuity (or instability) resulting from the military rotational cycle associated with military postings, training, and deployments. The following responses illustrate this theme:

Continuity of civilians in positions increases corporate knowledge. They are often the ones who have the history and background on issues. (Canada, military)

Because civilian personnel are not subject to the posting churn, they are able to build corporate knowledge in a position over time which makes them very valuable. (New Zealand, military)

\subsubsection{Learning opportunities}

The benefit of learning opportunities was the second most commonly mentioned theme by civilians and the fourth most commonly mentioned theme by military respondents. Responses in this theme often related to opportunities for learning through formal training and informal new experiences provided by the mixed military-civilian work environment. This theme also included comments regarding the opportunity to gain a greater understanding of the nature and/or importance of tasks that are performed by those in the "other" group. The following responses illustrate this theme:

The depth and wealth of experience and knowledge to be gained from each other. (The United Kingdom, military)

Learning from each other's experiences (general operation experiences vs. specialist knowledge) and learning from each other's culture. (The Netherlands, military)

As a civilian you see how the military works and not just the front line fighting being broadcast on the evening news. (The United Kingdom, civilian)

Learning from each other is a huge plus as I feel coming from a civilian working background I have contributed a lot of useful ideas to the team and implemented changes. (New Zealand, civilian)

\subsubsection{Positive culture}

Creation of a positive work culture was the fourth and fifth most commonly cited benefit of a mixed military-civilian work environment for civilians and military, respectively. Respondents indicated experiencing a sense of belonging in this type of environment, a supportive work environment, and appreciation of both military and civilian cultures. The following responses illustrate this theme:

The environment is relaxed, perhaps less strict and stringent. Many of my friends at work are civilian. (Canada, military) 
It becomes a totally different culture that is positively mixed. (Sweden, military)

The military has a particular culture and esprit-de-corps that civilians could learn and benefit from. (Canada, civilian)

Compared with other civilian organisations I believe the values that have grown out of the military context underpin the entire organisation in a very positive way. (New Zealand, civilian)

\subsubsection{Positive aspects of working in a mixed military- civilian environment: cross-national comparison}

Examining the responses cross-nationally, there was a great degree of agreement across nations regarding the positive aspects of working in a mixed military-civilian environment, as illustrated in Figure 4. Most notably, the benefit of diverse perspectives was the most commonly cited theme for all the nations. There were also some prominent cross-national differences. In particular, Swedish respondents were most likely to discuss the benefit of additional knowledge and skills (31.3\%), although this was a common response for all the nations. In contrast, Swedes were least likely to mention the benefit of stability and continuity (in fact none mentioned this theme), which is not surprising as they were the only nation that rarely mentioned unstable work environment as a challenge to working in a militarycivilian context, while respondents from New Zealand were somewhat more likely than others to mention this theme (21.7\%). Respondents from the Netherlands were somewhat more likely than those from other nations to mention learning opportunities as a benefit (20.2\%), and those from the United Kingdom were somewhat more likely than others to mention positive culture (13.8\%) and more efficient/effective performance $(11.2 \%)$ as benefits of working in a mixed military-civilian environment.

\subsection{Establishing and maintaining positive military-civilian work relations}

The third open-ended question asked respondents: "What do you consider to be the most important factors in establishing and maintaining positive military-civilian personnel work culture and relations?” A total of 1,521 military respondents and 2,099 civilian respondents provided answers to this question after accounting for responses that were deemed "not applicable." Figure 5 provides the percentages of military and civilian personnel that mentioned each respective theme in response to this question.

As shown in Figure 5, both military and civilian respondents most commonly indicated that respect, intergroup understanding and familiarity, ensuring fair and equitable treatment, effective communication, and opportunities for

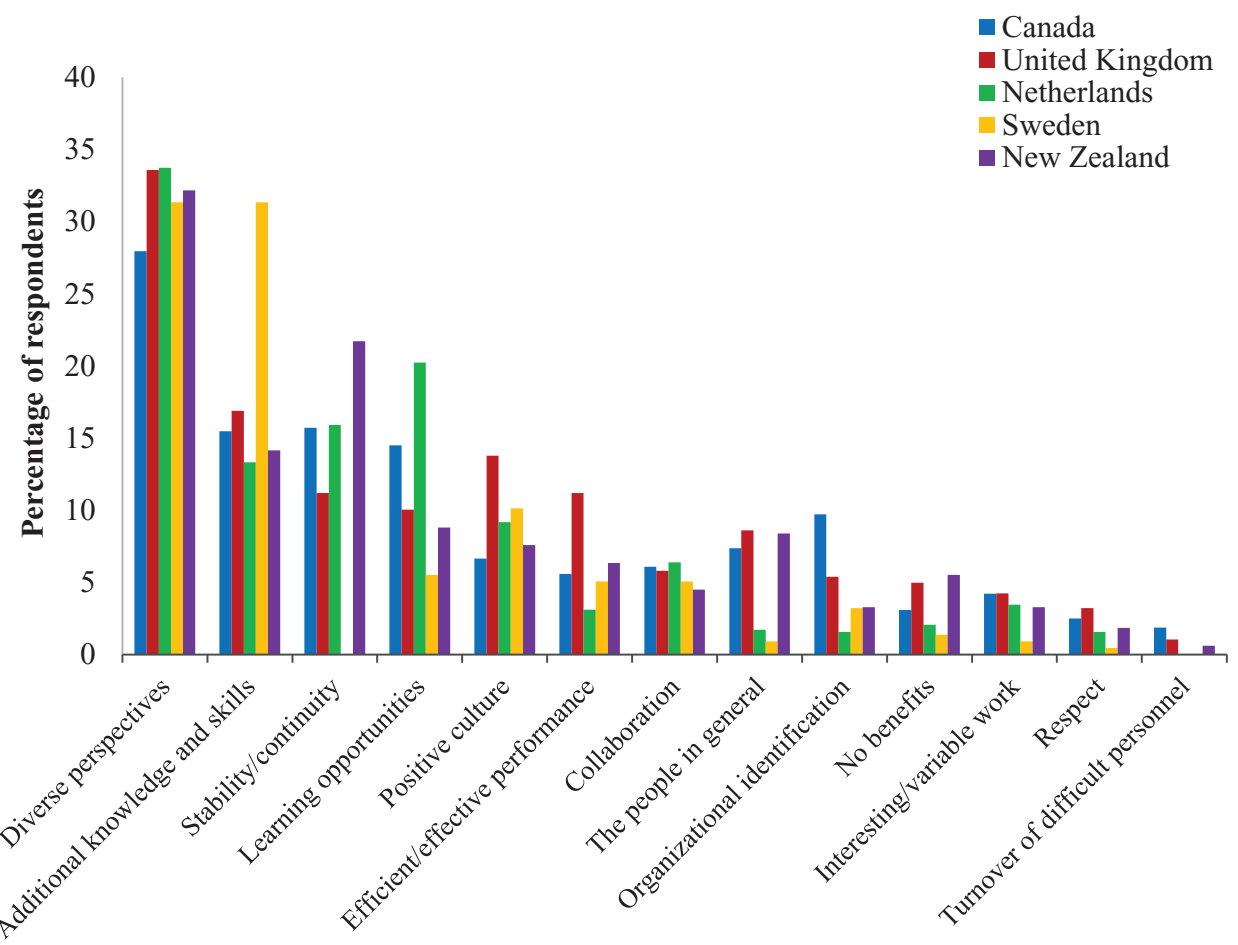

Fig. 4: Positive aspects of working in a mixed military-civilian environment. 


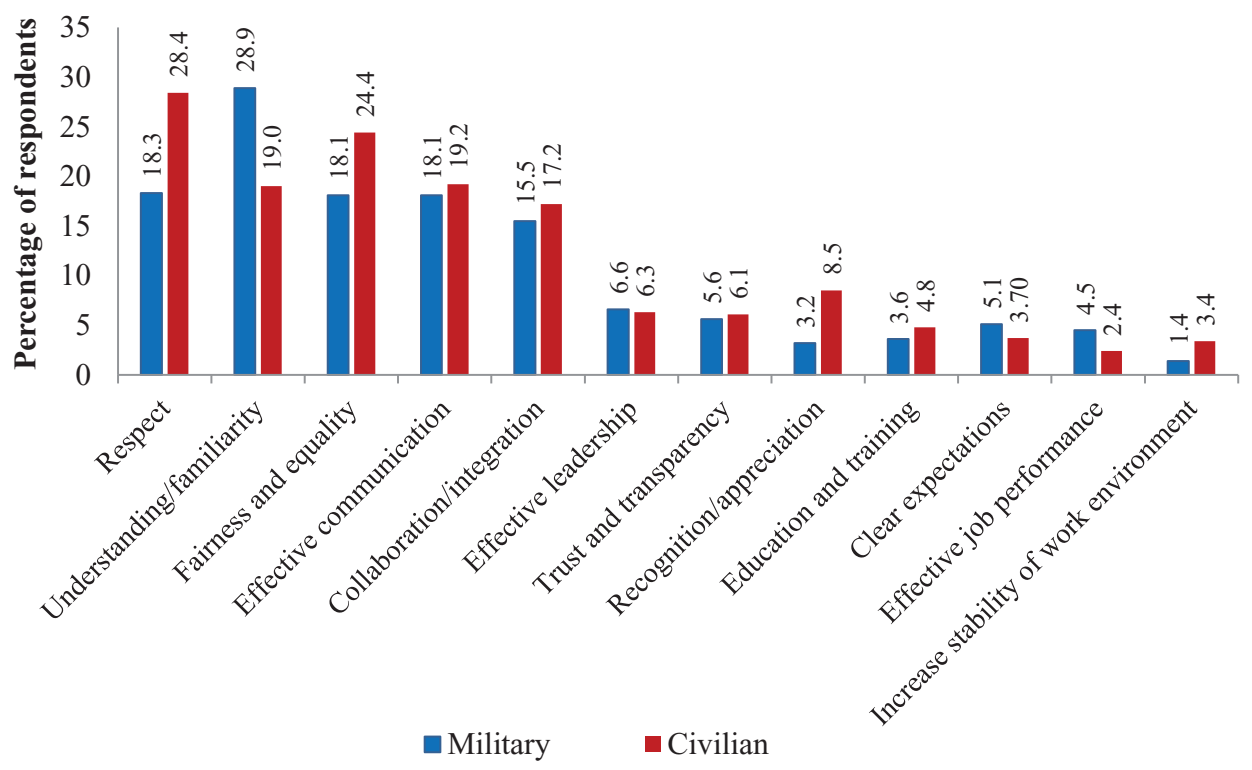

Fig. 5: Factors in establishing and maintaining positive military-civilian work relations.

intergroup collaboration and integration were the most important factors for establishing and maintaining positive military-civilian relations (these top five themes represent $75.9 \%$ of all theme categorizations for this question). Civilians were more likely than military personnel to indicate respect $(28.4 \%$ of civilians and $18.3 \%$ of military respondents mentioned this theme) and fairness/equality (24.4\% of civilians and $18.1 \%$ of military respondents mentioned this theme), whereas military personnel were more likely than civilians to mention intergroup understanding and familiarity $(19.0 \%$ of civilians and $28.9 \%$ of military respondents mentioned this theme). Effective communication and opportunities for intergroup interaction and collaboration were mentioned with approximately equal frequency by both groups. Each of these themes is elaborated below and illustrative examples are provided.

\subsubsection{Respect}

Respect was the most commonly cited factor by civilians and the second most commonly cited factor by military respondents when asked to indicate the most important factors for establishing and maintaining positive militarycivilian work relations. Responses in this theme related to the importance of having mutual respect, respect for group differences, respect for personnel regardless of affiliation or rank, and being respectful of each other's opinions. The following responses illustrate this theme:

Treating each other with respect and not imposing military ethos as the only option. (The United Kingdom, military)
To accept one another and treat each other with respect; respect and appreciate each other's knowledge and skills. (The Netherlands, civilian)

Respect for each other as human beings and professionals. (Sweden, civilian)

\subsubsection{Understanding/familiarity}

Intergroup understanding and familiarity was the most commonly cited factor by military personnel and the fourth most commonly cited factor by civilians. Responses in this theme related to the importance of understanding each other's perspectives, roles and tasks, terms and conditions of employment, cultures, and generally getting to know one another. The following responses illustrate this theme:

Knowledge of each other's background and competences. Understanding of each other's motivation to do the job; Understanding of each other's culture and point of view. (The Netherlands, military)

To engage civilian personnel to a higher extent in military matters in order to increase the understanding of the SAF. (Sweden, civilian)

Understanding of how each plays a part in the overall purpose of NZ and how each contributes to those outcomes. (New Zealand, civilian)

\subsubsection{Fairness and equality}

Ensuring fairness and equality was the second most commonly cited factor by civilians and the third most commonly cited factor by military respondents (same 
frequency as effective communication discussed below). This theme encompassed comments pertaining to fairness and/or equal treatment across many aspects of the military-civilian working environment, such as workload, pay, training opportunities, and recognition. The following responses illustrate this theme:

Maintaining equity across the board and ensuring that one group is not being treated differently to the other. (The United Kingdom, military)

Equal training, equal treatment when training is offered, equal wages, equal time off, equal medical and dental benefits. (Canada, civilian)

\subsubsection{Effective communication}

Effective communication was the fourth most commonly cited theme for both military and civilian respondents (same frequency as fairness discussed above). Comments coded within this theme pertained to the importance of communication in general as well as exchanging information, perspectives, and initiatives in a timely and effective manner. Some respondents also mentioned that frequent communication was important for establishing positive military-civilian work relations. The following responses illustrate this theme:

Communication about what you are doing, about the organization's direction. To create mutual objectives, more communication, good communication. (The Netherlands, military)

Regular communication and exchange of views. (The United Kingdom, civilian)

\subsubsection{Collaboration/integration}

Greater collaboration and integration was the fifth most commonly cited theme by both military and civilian respondents. Comments within this theme emphasized that establishing positive military-civilian work relations requires opportunities for military and civilian personnel to interact with one another, both professionally and socially, and to have opportunities to work closely together on common tasks and towards goals. The following responses illustrate this theme:

Joint tasks and activities; teambuilding; working in teams; working together towards one goal; solidarity. (The Netherlands, military)

The two cultures have some necessary differences, but they can collaborate to maximise results ... encourage more mixing or working together, to understand what the other side offers, and get used to how the other operates. (New Zealand, military)

Teamwork in the workplace. Social events, both during and after work hours. (Canada, civilian)

\subsubsection{Establishing and maintaining positive military- civilian work relations: cross-national comparisons}

As shown in Figure 6, respondents across the nations generally identified the same five factors as being important for establishing and maintaining positive militarycivilian personnel relations. Swedish responses were the most divergent overall, though still more similar than different in comparison with the other nations. Dutch respondents were most likely to mention respect as a key factor (33.9\%), whereas Swedish respondents (11.6\%), followed by those from New Zealand (16.8\%), were comparatively less likely to highlight respect. Understanding/familiarity and fairness/equality were mentioned with similar frequency across the nations, with the exception of Swedes who were somewhat less likely to discuss understanding/familiarity compared with the other nations (14.2\%). Effective communication was a common theme across all nations except Sweden, although Canadians (22.8\%), followed by those from the United Kingdom (19.7\%) were most likely to evince this theme. Opportunities for collaboration and integration were most likely to be evinced in Canada (20.4\%) and New Zealand (18.3\%), but relatively a common theme across the nations. Dutch respondents were comparatively more likely to indicate the importance of trust and transparency (though only 10.3\% indicated this theme), and those from the United Kingdom were comparatively more likely to indicate the importance of intergroup recognition and appreciation (though only $12.6 \%$ indicated this theme).

\section{Discussion}

\subsection{Summary}

Personnel in the five nations examined described in their own words the challenges, benefits, and enablers of working in a mixed military-civilian work environment. Military and civilian personnel identified the same 5-6 themes across each question, although there 


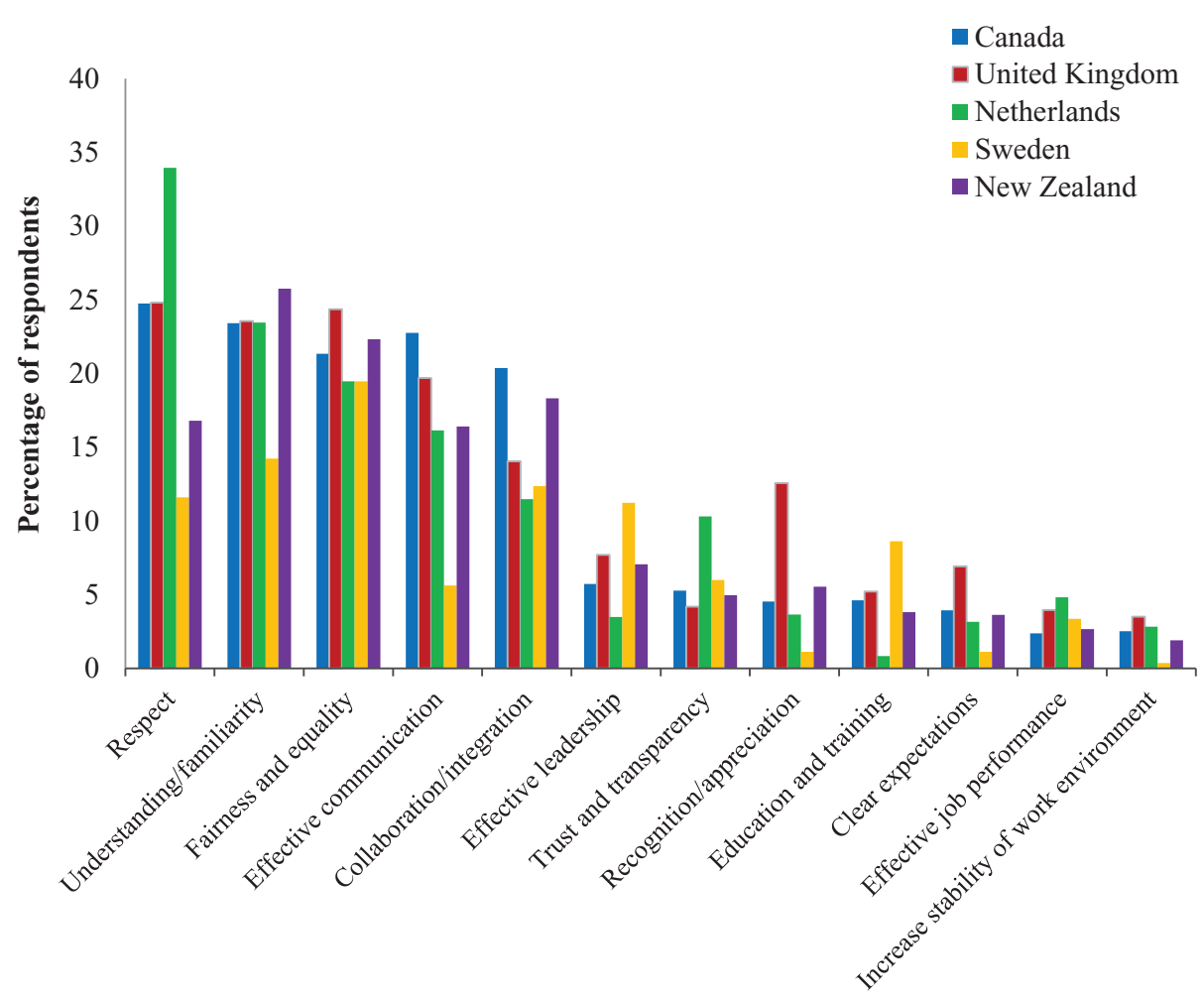

Fig. 6: Factors in establishing and maintaining positive military-civilian work relations.

were some differences between military members and civilians in the order of importance or frequency with which these were evinced, as noted below. The top six challenges identified overall (representing $70.6 \%$ of theme categorizations) were lack of understanding, poor attitude about others, cultural differences, lack of fairness or unequal treatment, perceived issues with work style or work ethic of one of the groups by the other group, and unstable work environment. The top five benefits (representing $70.2 \%$ of theme categorizations) were diverse perspectives, additional knowledge and skills, stability and continuity, learning opportunities, and benefits to organizational culture. Overall, military tended to highlight fewer main positive aspects (almost all of their responses centred on the four themes of diverse perspectives: additional knowledge and skills, stability and continuity, and learning opportunities), whereas civilians tended to discuss a greater range of factors. With respect to the most important factors for establishing and maintaining positive military-civilian work relations, both military and civilian respondents emphasized the importance of intergroup understanding and familiarity, respect, fairness and equitable treatment, opportunities for interaction and collaboration, and effective communication (these themes represented $75.9 \%$ of theme categorizations).

\subsection{Key themes}

Given that some themes consistently emerged across nations and in the responses of both military and civilian personnel across the questions, these themes likely represent some of the most important defining characteristics of working in an integrated military-civilian work environment and are discussed in greater detail below.

\subsubsection{Intergroup familiarity}

Understanding of the "other" group was a predominant theme across the questions. This included understanding what kind of work military and civilian personnel perform, familiarity with one another's roles, and understanding divergent work cultures. Overall, it was suggested that to ensure optimal partnership and collaboration among military and civilian personnel working together, there needs to be an understanding on both sides with respect to having a common vision of the mission, and an understanding of each other's perspectives and experiences. Opportunities for collaboration as well as interaction, both in terms of work tasks and social opportunities, were frequently suggested as facilitating intergroup familiarity. 


\subsubsection{Diverse perspectives and additional knowledge and skills}

The benefits of having input from the different perspectives of military and civilian personnel, as well as the complementary knowledge and skills of the two groups, were noted as key benefits resulting in improved organizational outcomes. At the same time, challenges with respecting these different perspectives or roles, including lack of appreciation of cultural differences and negative attitudes about the "other" group, were often evinced as key challenges. As such, it is not surprising that respect for each other's roles and perspectives as well as effective communication and opportunities for intergroup collaboration were emphasized as key enablers for capitalizing on the different perspectives, knowledge, and skills available in mixed military-civilian work contexts, and as important elements for mitigating the potential challenges.

\subsubsection{Fairness and equality}

Fairness and equality was another transcendent theme, emerging as a challenge of working in a mixed militarycivilian environment and also as an important factor to consider for establishing positive military-civilian personnel work culture and relations. Responses suggest that military and civilian personnel have concerns regarding the fairness of their pay, opportunities for training and development, career advancement, work arrangements, benefits, time off, and other policy-related issues. It is not surprising that this theme was often noted, given that fairness and equality is paramount in any type of diversity, including that inherent to military-civilian personnel differences.

\subsubsection{Stability and continuity in the workplace}

Workplace stability and continuity emerged as a main challenge and also a main benefit of working in a mixed military-civilian work environment. The comments of civilian personnel indicate that they perceive their work to be affected by the frequent postings and deployments of their military co-workers, whereas military personnel recognize the challenges that may be posed by frequent turnover of positions and value the continuity provided by their civilian counterparts to ameliorate these effects. The nature of these responses indicates that the military operational requirements related to postings, training, and deployments pose a challenge, particularly for civilians, whose responses frequently made mention of difficulties associated with retraining new military personnel or losing skilled co-workers due to postings, training, or deployments. These challenges were further compounded by difficulties associated with the change of priorities or management style experienced by personnel when a new military supervisor was posted in. Military personnel, on the other hand, emphasized the value of having a stable and knowledgeable force of civilian personnel who were capable of maintaining continuity and corporate knowledge over long periods of time and being prepared to offer support to military operations from home.

\subsection{Intergroup and cross-national comparisons}

Although military and civilian personnel identified common challenges, some notable differences also emerged. In particular, military personnel identified lack of understanding and issues with work style and work ethic as the key challenges, whereas these factors were endorsed less frequently by civilians. Conversely, civilians highlighted unstable work environment and poor attitudes about others as the key challenges, whereas these themes were indicated much less frequently by military personnel. Both groups identified unfairness and inequality as well as cultural differences with moderate frequency. With respect to benefits, although both military and civilian personnel identified diverse perspectives as the main benefit, military personnel were much more likely to endorse this theme as compared with civilians. Further, military were much more likely than civilians to indicate stability and continuity as being a key benefit. This pattern is not particularly surprising given that civilians were much more likely than military to indicate that one of their main challenges is unstable work environment. The two groups also identified very similar factors as being important for establishing and maintaining positive military-civilian work relations, with the same five factors emerging as being most important between these two groups of personnel. However, civilians were somewhat more likely than military personnel to indicate respect as a key factor and were also slightly more likely to identify fairness and equality as important, whereas military personnel were much more likely to indicate that understanding and familiarity with the other group is a key factor. These differences likely stem from the different personnel management systems (e.g. rotations of military personnel) and culture differences between the two 
groups (e.g. military being seen as the "teeth" while civilians are generally the "tail" whose main role is to support the military).

Despite a fair amount of cross-national variability in the responses, particularly in the case of Sweden, an overall pattern across nations emerged, with the most frequent themes being endorsed most often across the majority of the nations and with the least frequent themes being endorsed least often across the nations for the most part. The cross-national differences did not appear to follow a systematic pattern, and thus the reasons for these observed differences were not clear. Some of the variability may stem from differences in the level of importance attributed to the different themes based on different cultural and/or organizational factors, while some may be related to differences in research design and language. Follow-on research will focus on the prospective and explicit measurement of national organizational factors to enable the optimal analysis of their influence in predicting military-civilian collaboration.

\subsection{Theoretical frameworks}

Although this analysis was an exploratory empirical one, aimed at identifying factors related to military-civilian personnel integration in the first place, the results point to a number of theoretical frameworks that can be applied in future research to enhance our understanding in this domain. For example, according to social identity theory, an individual's identity is created when individuals place themselves and others into social categories, which is then followed by comparison among the groups (Tajfel and Turner 1986). In general, individuals hold favourable attitudes toward their own group and categorize other groups or "outgroups" as inferior (Hogg and Abrams 1988). Social attraction theory suggests that individuals are more attracted to and positively influenced by those who are similar to them with respect to attitudes, values, as well as more overt biodemographic characteristics such as sex and race, or as in our study, the presence of a uniform (Bryne 1971; Jackson et al. 1991; Lefkowitz 1994; Newcomb 1961). These theories can be instructive in understanding some of the challenges expressed, particularly negative attitudes towards those in the outgroup, critique of others' work styles, and lack of understanding or positive appreciation of cultural differences.

By contrast, the information-processing theory of organizational/team diversity speaks to the benefits of diverse teams, noting that the informational, educational, and functional background and expertise of diverse team members enhance performance by allowing members to draw on a variety of perspectives and approaches, as well as different sources of information and diverse perspectives (Phillips et al. 2004; Pitcher and Smith 2000). In a similar vein, the symbolic-interactionist perspective emphasizes the complementarity of roles in diverse teams, positing that the different strengths and weaknesses of different individuals or subgroups complement each other when combined with the strengths and weaknesses of other individuals or subgroups. For example, given that military personnel move in and out of positions more frequently than civilians do due to operational requirements related to postings and deployments, unstable work environment was a commonly cited challenge of military-civilian integration, particularly by civilian respondents. However, this rotational cycle might bring a greater breadth of experience to the team, while civilian personnel who tend to remain in the same positions for more extended periods might bring a greater depth of experience in a given domain (e.g. corporate knowledge). Indeed, stability and continuity offered by civilian personnel was one of the main benefits of military-civilian integration identified by military respondents. Taken together, these frameworks clearly reflect the diverse perspectives and additional knowledge and skills themes which were the two most prominent benefits identified by our respondents, as well as the instrumental benefit of added stability and knowledge management provided by civilians in light of the military rotational cycle, while military are seen to bring with them not only military expertise but also a greater breadth of experience that can benefit the work of the group.

Allport's (1954) contact hypothesis, which has been widely researched and validated (Patchen 1999; Pettigrew 1998; Pettigrew and Tropp 2006), contends that bringing people together and exposing them to each other's positive qualities will reduce prejudices and facilitate more positive attitudes and interactions. Moreover, as Allport proposed, follow-on research demonstrated that although positive intergroup contact effects were strongest when certain ideal preconditions were met (e.g. equal status, common goals, support of authorities/customs), these conditions were not critical to reduce negative attitudes and that intergroup contact has the ability to reduce prejudice even in the absence of these conditions, although interaction under these facilitating conditions typically leads to the greatest benefits (Pettigrew and Tropp 2006). Indeed, increased opportunities for integration and collaboration, as well 
as increased opportunities to interact socially, was one of the most commonly suggested mechanisms for establishing and maintaining positive intergroup relations. Greater contact can also help to reduce some of the identified challenges by correcting inaccurate information and increasing understanding of one another's roles, cultures, and work styles or regulations.

Fairness and equal or respectful treatment were also identified as key enablers of military-civilian collaboration, highlighting the potential for application of a number of interrelated theories in this domain. For example, social comparison theory (Buunk and Gibbons 2007; Festinger 1954) postulates that people naturally compare themselves and their circumstances to those of others as a way of understanding the world, and that downward social comparisons (i.e. comparing oneself to someone who is "worse off") generally makes people feel better, whereas upward comparisons (i.e. comparing oneself to someone who is "better off") generally makes people feel worse (Baumeister and Bushman 2013; Wheeler and Miyake 1992). Research on organizational justice theory, defined as the degree to which individuals believe they are treated fairly within their organizations and the degree to which outcomes they receive are allocated in a fair manner (Cropanzano et al. 2007), indicates that perceptions of organizational justice affect employee well-being, behaviour, and retention (Ambrose and Schminke 2009; Kim and Leung 2007; Masterson et al. 2000). Equity theory (Adams 1963, 1965), which evolved, in part, out of social comparison theory, and also drew on exchange and dissonance theories, focuses on aspects of exchange and on comparison of what is contributed in relation to what is received, disparity in which it can lead to perceptions of inequality, and in turn, other negative feelings (Huserman et al. 1987). Since military and civilians work closely together, yet under different personnel management systems with distinct conditions of service or employment, observing these differences and thus the potential for perceiving inequality or unfairness are likely. By the same token, factors such as increasing intergroup understanding and familiarity and effective communication can help to mitigate misperceptions and provide insight into the reasons behind intergroup differences in benefits, privileges, or working conditions. These, in turn, can help to reduce perceptions such as the commonly cited challenge of unfairness and inequality, as well as lack of understanding of operating requirements, cultural misperceptions, and negative attitudes. Equitable treatment, to the degree possible, in light of the different roles and management systems of personnel in the two workforces, is of course paramount as well.

\section{Conclusion}

Overall, the responses to the open-ended questions in this cross-national survey indicate that mixed military-civilian work environments present both unique challenges and benefits. For example, military and civilian personnel frequently cited challenges associated with fair treatment and a lack of understanding of each other's roles, cultures, and perspectives and reported experiencing challenges with the stability of their work environment related to the military rotational cycle. By the same token, the respondents also mentioned many ways in which military and civilian personnel complement each other, by providing complementary knowledge/expertise, diverse perspectives, support, and continuity. Given the general cross-national patterns, these findings provide useful insights for enhancing military and civilian personnel integration and collaboration for many nations. As such, application of these findings is likely to improve the working environment for both groups and thus enhance military-civilian collaboration in general.

\section{Acknowledgements}

The authors are grateful to the New Zealand Defence Force and to Dr. Sarah Overdale, for recognizing the importance of military-civilian personnel collaboration in defence organizations and for the significant time and effort required to administer the MCPS to their NZDF personnel.

\section{References}

Adams, J. S. (1963). Toward an understanding of inequity. Journal of Abnormal and Social Psychology, 7, pp. 422-436.

Adams, J. S. (1965). Inequity in social exchange. In: Berkowitz, L. (ed.), Advances in Experimental Social Psychology, Vol. 2. Academic Press, New York, NY, pp. 67-299.

Allport, G. W. (1954). The Nature of Prejudice. Perseus Books, Cambridge, MA.

Ambrose, L. M., \& Schminke, M. (2009). The role of overall justice judgements in organizational justice research: A test of mediation. Journal of Applied Psychology, 94, pp. 91-500.

Australian Ministry of Defence. (2014). First Principles Review: Creating One Defence. Available at: https://www.defence. gov.au/Publications/Reviews/Firstprinciples/Docs/ FirstPrinciplesReviewB.pdf

Baumeister, R. F., \& Bushman, B. J. (2013). Social Psychology and Human Nature, Brief, 3rd edn. Wadsworth Publishing, Belmont, CA. 
Bremner, N., Butler, A., \& Budgell, G. (2013). The Defence Team Survey: Qualitative Analysis (Director General Military Personnel Research and Analysis Contract Report 2013-031). Defence Research and Development Canada, Ottawa, ON.

Bryne, D. (1971). The Attraction Paradigm. Academic Press, New York.

Buunk, A. P., \& Gibbons, F. X. (2007). Social comparison: The end of a theory and the emergence of a field. Organizational Behavior and Human Decision Processes, 102, pp. 3-21.

Cropanzano, R., Bowen, D. E., \& Gilliland, S. W. (2007). The management of organizational justice. Academy of Management Perspectives, 21, pp. 34-48.

Dunigan, M., Schwille, M., Søndergaard, S., Everingham, S. S., \& Nichols, T. (2018). Expeditionary civilians: Creating a viable practice of civilian deployment within the United States. In: Goldenberg, I., \& Febbraro, A. R. (eds.), Civilian and Military Personnel Integration and Collaboration in Defence Organizations, pp. 353-381. NATO Science and Technology Organization Technical Report - STO-TR-HFM-226. doi: 10.14339/STO-TR-HFM-226.

Festinger, L. (1954). A Theory of Cognitive Dissonance. Stanford University Press, Stanford.

Goldenberg, I. (2013). The Defence Team Survey: Research Highlights (Scientific Brief CMP/AFC DTN 2013-6477). Director General Military Personnel Research and Analysis. National Defence Headquarters, Ottawa, Ontario, Canada.

Goldenberg, I. (2014). International Comparative Research. In: Presented at the Fifth Meeting of NATO STO HFM RTG-226. Berlin, Germany.

Goldenberg, I., Andres, M., Annen, H., Dautovic, K., Heiss, A., James-Yates, S., et al. (2018a). Military-Civilian Personnel Survey (MCPS): Descriptive cross-national analyses. In: Goldenberg, I., \& Febbraro, A. R. (eds.), Civilian and Military Personnel Integration and Collaboration in Defence Organizations, pp. 170-192. NATO Science and Technology Organization Technical Report - STO-TR-HFM-226. doi: 10.14339/STO-TR-HFM-226.

Goldenberg, I., Andres, M., Annen, H., Dautovic, K., Heiss, A., James-Yates, S., et al. (2018b). Conceptual model of militarycivilian personnel collaboration: Cross-national correlational results of the Military-Civilian Personnel Survey (MCPS): Descriptive cross-national analyses. In: Goldenberg, I., \& Febbraro, A. R. (eds.), Civilian and Military Personnel Integration and Collaboration in Defence Organizations, pp. 193-215. NATO Science and Technology Organization Technical Report - STO-TR-HFM-226. doi: 10.14339/STO-TRHFM-226.

Goldenberg, I., Andres, A., Gora, A., James-Yates, S., Jermalavičius, T., Johansson E., et al. (2018c). Military-Civilian Personnel Survey (MCPS): Cross-national qualitative analysis. In: Goldenberg, I., \& Febbraro, A. R. (eds.), Civilian and Military Personnel Integration and Collaboration in Defence Organizations, pp. 235-276. NATO Science and Technology Organization Technical Report - STO-TR-HFM-226. doi: 10.14339/STO-TR-HFM-226.

Goldenberg, I., \& Febbraro, A. R. (2018a). Civilian and Military Personnel Integration and Collaboration in Defence Organizations: Summary and Recommendations (NATO Science and Technology Organization Technical Report - STO-TR-HFM-226). doi: 10.14339/STO-TR-HFM-226.
Goldenberg, I., \& Febbraro, A. R. (2018b). Civilian and Military Personnel Integration and Collaboration in Defence Organizations (NATO Science and Technology Organization Technical Report - STO-TR-HFM-226). doi: 10.14339/STO-TR-HFM-226.

Hogg, M., \& Abrams, D. (1988). Social Identification. Routledge, London.

Huserman, R. C., Hatfield, J. D., \& Miles, E. W. (1987). A new perspective on equity theory: The equity sensitivity construct. The Academy of Management Review, 12, pp. 222-234.

Jackson, S., Brett, J. F., Sessa, V. I., Cooper, D. M., Julin, J. A., \& Peyronnin, K. (1991). Some differences make a difference: Individual dissimilarity and group heterogeneity as correlates of recruitment, promotions and turnover. Journal of Applied Psychology, 76, pp. 675-689.

Kim, T. Y., \& Leung, K. (2007). Forming and reacting to overall fairness: A cross-cultural comparison. Organizational Behavior and Human Decision Processes, 104, pp. 83-95. doi: 10.1016/ j.obhdp.2007.01.004.

Kochems, A. (2006). When should the government use contractors to support military operations? Backgrounder, 1938, pp. 1-5. The Heritage Foundation.

Lalonde, S. C. (2011). Canadian Forces Health Services: Factors Affecting the Retention of Public Service Health Care Professionals in the Department of National Defence (Technical Memorandum, DGMPRA TM 2011-013). Director General Military Personnel Research and Analysis, Department of National Defence.

Lefkowitz, J. (1994). Race as a factor in job placement: Serendipitous findings of "ethnic drift". Personnel Psychology, 47, pp. 497-513.

Masterson, S. S., Lewis, K., Goldman, B. M., \& Taylor, M. S. (2000). Integrating justice and social exchange: The differing effects of fair procedures and treatment of work relationships. Academy of Management Journal, 43, pp. 738-748. doi: $10.2307 / 1556364$.

Mastroianni, G. (2018). Military education: Clash of cultures? In: Goldenberg, I., \& Febbraro, A. R. (eds.), Civilian and Military Integration and Collaboration in Defence Organisations. NATO Science Technology Organisation, Paris, France, pp. 15-11.

McKee, B., \& Williams, L. M. (2007). Civilian Well-Being and Retention Project: Qualitative Findings (Sponsor Research Report 2007-14). Director Personnel Applied Research, Department of National Defence.

Newcomb, T. M. (1961). The Acquaintance Process. Holt, Rinehart, and Winston, New York.

Österberg, J., \& Johansson, E. (2018). Military-civilian personnel: Sweden country report. In: Goldenberg, I., \& Febbraro, A. R. (eds.), Civilian and Military Personnel Integration and Collaboration in Defence Organizations, pp. 117-121. NATO Science and Technology Organization Technical Report - STO-TRHFM-226. doi: 10.14339/STO-TR-HFM-226.

Parry, E., Connelly, V., Robinson, T., Morrison, Z., \& Taylor, C. (2016). Integration of the Whole Force: Understanding Barriers and Enablers to Task and Team Performance (O-DHCSTC 12_P_T2_083/004). Defence Human Capability Science and Technology Centre.

Patchen, M. (1999). Diversity and Unity: Relations between Racial and Ethnic Groups. Nelson-Hall, Chicago.

Pennell, B., Levenstein, R., \& Lee, H. J. (2011). Data collection: General considerations. Guidelines for Best Practices in 
Cross-Cultural Surveys. Survey Research Center, Institute for Social Research, University of Michigan, Michigan, pp. XII1-XII65.

Pettigrew, T. F. (1998). Intergroup contact theory. Annual Review of Psychology, 49, pp. 65-85.

Pettigrew, T. F., \& Tropp, L. R. (2006). A meta-analytic test of intergroup contact theory. Journal of Personality and Social Psychology, 90, pp. 751-783.

Phillips, K., Mannix, E., Neale, M., \& Gruenfeld, D. (2004). Diverse groups and information sharing: The effect of congruent ties. Journal of Experimental Social Psychology, 40, pp. 497-510.

Pitcher, P., \& Smith, A. D. (2000). Top management team heterogeneity: Personality, power and proxies. Organization Science, 12(1), pp. 1-18.

Schaub, G. Jr., \& Kelty, R. (2016). Private Military and Security Contractors: Controlling the Corporate Warrior. Rowman \& Littlefield, Maryland.
Schwartz, M., \& Church, J. (2013). Department of Defense's use of contractors to support military operations: Background, analysis, and issues for congress. Congressional Research Service, 1-32. Available at: https://apps.dtic.mil/dtic/tr/ fulltext/u2/a590715.pdf

Shaw, D., \& James-Yates, S. (2018). Tensions between military and civilian staff in the United Kingdom defence equipment and support organisation: A case study. In: Goldenberg, I., \& Febbraro, A. R. (eds.), Civilian and Military Integration and Collaboration in Defence Organisations. NATO Science Technology Organisation, Paris, France, pp. 16-11.

Tajfel, H., \& Turner, J. (1986). The social identity of intergroup behavior. In: Worchel, S., \& Austin, W. (eds.), Psychology and Intergroup Relations. Nelson-Hall, Chicago, pp. 7-24.

Wheeler, L., \& Miyake, K. (1992). Social comparison in everyday life. Journal of Personality and Social Psychology, 62, pp. 760-773. 